\title{
Formação de Professores da América Latina em Tecnologias Assistivas
}

\section{Latin American Teachers' Formation in Assistive Technologies}

Resumo: Contemporâneas Políticas Públicas de Educação Especial na Perspectiva da Educação Inclusiva têm nas Salas Multifuncionais e na Formação Continuada de Professores duas importantes ações governamentais para concretização da inclusão escolar. Pesquisas exploratórias realizadas nas Salas Multifuncionais, em municípios gaúchos, apontaram para a frágil formação dos professores na utilização de tecnologias assistivas para a promoção de práticas para qualificar processos de Atendimento Educacional Especializado. Este artigo apresenta uma das possíveis respostas para o desafio de capacitar educadores para a Educação Inclusiva - o Programa Nacional de Formação de Professores - da Secretaria de Educação Continuada, Alfabetização, Diversidade e Inclusão, do Ministério da Educação e Cultura (SECADI/MEC), que objetiva fornecer subsídios teóricos e metodológicos sobre as tecnologias digitais acessíveis, com ênfase nas Tecnologias Assistivas, para professores do Brasil e de países ibero-americanos. Com a apropriação do campo de saber da Tecnologia Assistiva viabiliza-se, no tempo e no espaço escolares, uma cultura relacionada à inclusão escolar.

Palavras-chave: Salas de Recursos Multifuncionais. Formações de Professores. Tecnologia Assistiva. Inclusão Escolar.

\begin{abstract}
The Contemporary Public Policies of Special Education in the perspective of inclusive education has Multifunctional Rooms and continuous teacher formation as two important governmental actions to concretize this inclusion of human diversity in the regular education. The exploratory researches carried out in Multifunctional Rooms in cities of Rio Grande do Sul show a weak teacher formation for the utilization of Assistive Technology and the promotion of actions to qualify the processes of Specialized Educational Service. This article presents one of the possible answers for the challenge of capacitating the educator for the Inclusive Education - The Teacher Formation National Program, from the Secretary of Continuous Education, Literacy, Diversity and Inclusion, of the Ministry of Education and Culture (SECADI/MEC) - which aims to provide theoretical and methodological supports for the available digital technologies, mainly for the Assistive Technology, to teachers in Brazil and Ibero-American countries. By the knowledge appropriation of the Assistive Technology the culture related to school inclusion becomes viable in the school and time and space.

Keywords: Multifunctional Resource Rooms. Teachers' Formation. Assistive Technology. School Inclusion
\end{abstract}

SANTAROSA, Lucila Maria Costi; CONFORTO, Débora. Formação de Professores da América Latina em Tecnologias Assistivas. Informática na Educação: teoria e prática, Porto Alegre, v. 15, n. 2, p. 75-93, jul./dez. 2012.

\section{Lucila Maria Costi Santarosa \\ Débora Conforto}

Universidade Federal do Rio Grande do Sul

\section{I ntrodução}

A inclusão, como fenômeno social, tem suas raízes na cultura, extrapolando os aspectos meramente escolares. A presença da heterogeneidade nos diferentes espaços socioculturais tem, numa relação de imanência, projetado políticas públicas de atenção à diversidade humana sob o tripé educação, saúde e assistência social. A partir dessa perspectiva, uma forma muito particularizada de abordar a deficiência orgânica ou a fragilidade psicológica foi instituída - o aluno especial para a Educação Especial, o paciente para a saúde, o beneficiário para a assistência social - produzindo ações isoladas e projetos desarticulados que dificultam 
o reconhecimento das múltiplas dimensões da vida humana.

Hoje, a visão de necessidades especiais engloba um conjunto de aspectos que ultrapassa o antigo conceito de deficiente. Essa mudança de deficiência para necessidade especial traz consigo a concepção da variabilidade humana e forja importantes deslocamentos - do caráter permanente para o transitório, da visão de adaptar a pessoa deficiente para a visão de viver na sociedade para a inclusão, pela adaptação da sociedade com a superação das barreiras que impõem desvantagens para a efetiva participação de sujeitos com necessidades especiais em contextos socioculturais.

O respeito e a valorização da diversidade humana efetivam-se por meio do deslocamento do verbo acolher, a simples união de diferentes grupos, sem um projeto que institua uma nova percepção para a diferença, para o verbo incluir, quando políticas públicas projetam e constroem a ação de pertencer. Para que se configure uma prática de inclusão, é preciso que bases teóricas de respeito à heterogeneidade e que suportes técnicometodológicos necessários à mediação sejam discutidos e apropriados pela sociedade em sua totalidade e, em especial, por educadores e gestores de sistemas escolares contemporâneos.

A garantia de processos de escolarização para todos passou a exigir dos professores do ensino regular conhecimentos específicos sobre os alunos com necessidades especiais, não mais sob a luz do seu possível déficit, mas, fundamentalmente, na valorização de suas potencialidades e possibilidades. Com a proposta da Educação Inclusiva, a escolarização no Brasil assumiu como premissa a indissociabilidade da teoria e da prática e a concepção de um processo educativo que necessita ser transformado, ressignificado e reinventado.

Os saberes e a materialidade das tecnologias digitais acessíveis, em especial da Tecnologia Assistiva, podem desencadear, potencializar e efetivar um processo de respeito e de valorização da heterogeneidade, princípios que modelam uma educação igualitária e equitativa, quando esse campo do conhecimento também passa a compor o leque de habilidades e de competências dos educadores. Pretendemos, com esse artigo, colocar em evidência a importante complementaridade das ações governamentais no âmbito da Educação. Disponibilizar recursos tecnológicos e capacitar educadores na utilização de tecnologias digitais acessíveis são faces de uma mesma moeda, ações fundamentais para impulsionar a operacionalidade da Educação Inclusiva por meio da qualificação do atendimento educacional especializado $\left(A E E^{1}\right)$ no tempo e no espaço escolares.

\section{Educação Inclusiva: imperativo da formação docente}

Embora, nos últimos anos, o crescimento na área da inclusão sociodigital e escolar sejam inegáveis, ainda se vivencia uma realidade brasileira não favorável para a diversidade humana, fato comprovado pela quantidade de sujeitos ainda colocados na exteriorida-

\footnotetext{
${ }^{1}$ De acordo com o decreto № 6.571/2008, “[...] considera-se atendimento educacional especializado o conjunto de atividades, recursos de acessibilidade e pedagógicos organizados institucionalmente, prestado de forma complementar ou suplementar à formação dos alunos no ensino regular" (BRASIL, 2008).
} 
de de processos educativos na rede escolar. Somam-se a esse fato, a dura realidade das condições de trabalho docente e a frágil formação dos professores, aspectos que têm impulsionado posições reducionistas centradas nas limitações e nas dificuldades do sistema de ensino regular em atender a diferença e a deficiência.

A contemporânea Política Nacional de Educação Especial na Perspectiva da Educação Inclusiva, ao mesmo tempo em que configura o cenário educacional brasileiro sob o conceito da diferença, implementa dois importantes programas para sua concretização: a distribuição de Salas de Recursos Multifuncionais e a Formação Continuada de Professores na Perspectiva da Educação Inclusiva. O primeiro programa projeta, na escola regular, espaços para apoiar a organização e a oferta de atendimento educacional, enquanto o segundo tem por objetivo formar professores dos sistemas estaduais e municipais de ensino por meio da constituição de uma rede nacional de instituições públicas de educação superior na oferta de cursos de formação continuada para professores, na modalidade a distância. O programa de formação docente é ofertado às redes estaduais e municipais de Educação que tenham solicitado a formação continuada de professores em seu Plano de Ações Articuladas (PAR) e que tenham sido contempladas pelo Programa de I mplantação de Salas de Recursos Multifuncionais.

A Sala de Recursos Multifuncionais é o espaço na instituição educativa que identifica e organiza recursos pedagógicos e de acessibilidade para potencializar a plena participação de alunos com necessidades especiais em todos os lugares da escola, em especial, na sala de aula. Partindo da identificação dos pontos de fragilidade e das potencialidades de cada aluno com necessidades especiais, a Sala de Recursos Multifuncionais é o espaço por excelência no cenário escolar para aproximar a diversidade humana e as Tecnologias Assistivas. As ações desencadeadas na Sala de Recursos Multifuncionais têm o caráter complementar ou suplementar à formação do aluno, "[...] não sendo substitutivas à escolarização" (BRASIL, 2009, p. 10).

O número crescente de escolas brasileiras contempladas com as Salas de Recursos Multifuncionais atesta a preocupação do Ministério da Educação quanto ao cumprimento dessa ação governamental para, assim, impulsionar e qualificar a construção de estratégias educativas em apoio ao atendimento educacional especializado. Entretanto, pesquisas realizadas por Emer (2011) e por Rodrigues (2011), ambas em municípios gaúchos, colocaram em evidência o desconhecimento dos educadores que atuam nas Salas de Recursos Multifuncionais em relação ao campo de saber da Tecnologia Assistiva, principalmente, quanto à possibilidade de esses recursos tecnológicos atuarem com interfaces de inclusão sociodigital na escola e para além dos muros da escola. A fala de uma professora que atua no atendimento educacional especializado e que participou como sujeito de pesquisa nas investigações realizadas por Rodrigues (2011) ilustra que a presença da Tecnologia Assistida na escola não é suficiente para que esse recurso seja desencadeador de movimentos individuais e coletivos de inclusão: “[...] a gente quer entender, a gente quer saber e poder usar, não só saber que tem" (RODRIGUES, 2011, p. 164). Esse aspecto também se faz presente na análise de Emer (2011, p. 22): “[...] passei a observar 
que a rede pública recebia equipamentos e softwares destinados a apoiar o processo de inclusão, mas que esses continuavam lacrados, pelo simples fato de ninguém ter conhecimento apropriado para utilizá-los".

Participaram da pesquisa exploratória realizada por Emer (2011), 31 professores, em 15 escolas contempladas com as Salas de Recursos Multifuncionais, em dois municípios da serra gaúcha. Por meio de observações e entrevistas e da dinâmica de Grupos Focais, foi possível analisar a atuação desses profissionais e revelar a importância da formação dos recursos humanos, principalmente no âmbito da Tecnologia Assistiva, para a concretização de processos de inclusão escolar. A caracterização dos sujeitos que participaram dessa pesquisa permite apontar para um importante aspecto: a idade dos professores que atuam em escolas com Salas de Recursos Multifuncionais. Nesse universo pesquisado, os recursos humanos que atuam no Atendimento Educacional Especializado não fazem parte da Geração Y ou Geração Internet, grupo etário nomeado pela Psicologia e pela Sociologia para se referir aos nascidos após 1980, a geração multitarefa, muito envolvida com tecnologia e novas mídias, totalmente criada na Era Digital.

A relação entre a idade dos professores em atuação nas Salas de Recursos Funcionais e os recursos utilizados para mediar ações relacionadas ao Atendimento Educacional Especializado está diretamente vinculada ao distanciamento dos recursos de hardware e de software, optando pela utilização de Tecnologias Assistivas de baixa tecnologia: “[...] o que mais utilizo são jogos pedagógicos como de letras, números, memória, quebracabeça [...] utilizo bola, corda, bastão, arcos, materiais para desenvolver a psicomotricidade" (EMER, 2010, p.24).

Pesquisa exploratória realizada pela Comissão Temática da Educação, do Comitê de Ajudas Técnicas, da Subsecretaria Nacional de Promoção dos Direitos da Pessoa com Deficiência, e que teve como objetivo analisar o uso de recursos e equipamentos de Tecnologia Assistiva para auxiliar alunos com deficiência no desempenho de suas atividades educacionais, revelou o desconhecimento dos educadores quanto à aplicabilidade e ao manuseio de Tecnologias Assistivas:

[...] Os dados preliminares indicam dois caminhos para os quais as ações das políticas públicas para o atendimento do aluno com deficiência possam se direcionar: (1) a necessidade urgente de aquisição de recursos equipamentos de Tecnologias Assistiva; (2) a necessidade de capacitação para uso desses recursos e equipamentos. (BRASIL, 2009, p. 56)

A Tabela 1 apresenta a listagem das Tecnologias Assistivas que foi enviada para as instituições educativas e, em paralelo, as informações quanto ao conhecimento dos professores em relação à aplicabilidade e ao manuseio dessas tecnologias.

TABELA 1 - Tecnologia Assistiva $X$ Conhecimento Docente

\begin{tabular}{|c|c|c|}
\hline \multirow{2}{*}{ Tecnologia Assistiva } & \multicolumn{2}{|c|}{$\begin{array}{c}\text { Sabe manu- } \\
\text { sear }\end{array}$} \\
\cline { 2 - 3 } & Sim & Não \\
\hline $\begin{array}{c}\text { Software para a criação de pranchas } \\
\text { de comunicação }\end{array}$ & 4 & 26 \\
\hline $\begin{array}{c}\text { Notebook com programas para alunos } \\
\text { com deficiência física }\end{array}$ & 6 & 23 \\
\hline $\begin{array}{c}\text { Computador com programas para alu- } \\
\text { nos com deficiência física }\end{array}$ & 8 & 21 \\
\hline Acionador para computador & 6 & 23 \\
\hline Lupas eletrônicas & 1 & 30 \\
\hline Impressora Braille & 3 & 25 \\
\hline
\end{tabular}




\begin{tabular}{|c|c|c|}
\hline Duplicador Braille & 0 & 31 \\
\hline Calculadora que fala em português & 7 & 23 \\
\hline $\begin{array}{c}\text { Notebook com programas para alunos } \\
\text { com deficiência visual }\end{array}$ & 5 & 24 \\
\hline $\begin{array}{c}\text { Computador com software para o alu- } \\
\text { no cego/baixa visão }\end{array}$ & 5 & 25 \\
\hline $\begin{array}{c}\text { Software para alunos com deficiência } \\
\text { visual }\end{array}$ & 4 & 26 \\
\hline $\begin{array}{c}\text { Computador com programas específi- } \\
\text { cos para deficiência auditiva }\end{array}$ & 14 & 14 \\
\hline $\begin{array}{c}\text { Notebook com programa específicos } \\
\text { para deficiência auditiva }\end{array}$ & 8 & 19 \\
\hline
\end{tabular}

FONTE: Tabela adaptada. (BRASIL, 2009)

Os dados apresentados na Tabela 1 apontam para a importância de os professores e, em especial, os responsáveis pelas Salas de Recursos Multifuncionais, conhecerem e manusearem altas tecnologias assistivas, ou seja, as tecnologias diretamente relacionadas à Era Digital. Dar o enfoque também para as altas tecnologias nos currículos dos programas de formação dos educadores para a Educação Inclusiva é dar significado para os recursos técnicos que já estão disponíveis nas escolas de muitos municípios brasileiros.

A inserção de recursos tecnológicos no cenário escolar deve ser acompanhada de um processo de formação entrelaçado com o contexto de atuação do educador, para fazêlo assumir o perfil de pesquisador e, principalmente, de problematizador de sua prática pedagógica. Observar, pesquisar, planejar, executar, refletir e dialogar de forma constante com a realidade educacional são ações que devem estruturar o processo de formação docente também para as Tecnologias Assistivas, para forjar o perfil do professor-pesquisador idealizado por Paulo Freire (1996) e, assim, romper com o aspecto apontado por Rodrigues:
[...] a sensação que vivencio e que presenciei neste período de pesquisa é que quando se fala de tecnologias assistivas, organiza-se certo "pavor" ou, ao contrário "a salvação" para os problemas de acessibilidade. "Pavor", pois antecipadamente cria-se uma barreira, a do não saber; e "'salvação", pois o recurso é visto isoladamente, é usar e pronto, não considerando que a utilização do mesmo envolve planejamento constante e, principalmente, o papel de mediador que o profissional precisa assumir. (RODRIGUES, 2011, p. 172)

\section{Tecnologias Digitais Acessíveis: formar para impulsionar a Educação Inclusiva}

Ao dar visibilidade aos resultados dessas pesquisas, apontamos para a relevância de cursos de formação de professores na perspectiva da Educação Inclusiva, para posteriormente apresentar o curso em Tecnologias Digitais Acessíveis, que estabelece como fio condutor de suas ações a apropriação técnico-pedagógica.

A configuração da Educação Inclusiva traz benefícios para a sociedade e para todos os envolvidos no processo educativo, pois propicia a criação de um ambiente escolar e social em que os indivíduos aprendem a respeitar, a compreender e a admirar as qualidades de TODOS, independentemente de suas diferenças físicas e cognitivas, aspectos que possibilitam a efetivação de uma sociedade com justiça e equidade social. O Brasil vem desenvolvendo um processo de inclusão por meio das Políticas Públicas de apoio à Educação Inclusiva e dos projetos de Formação Continuada de Professores. O Ministério da Educação (MEC) assumiu como premissa a 
indissociabilidade entre teoria e prática e a concepção de um processo educativo que necessita ser transformado e reinventado.

Explicitando ideais de justiça e equidade social, a Rede de Formação Continuada de Professores, da Secretaria de Educação Continuada, Alfabetização, Diversidade e Inclusão (SECADI/MEC) gerencia e financia cursos de aperfeiçoamento, extensão e especialização na modalidade a distância, visando à capacitação de professores na perspectiva da Educação I nclusiva. Das inúmeras possibilidades de recursos e de formas de apoio que se apresentam no cenário educativo contemporâneo, as tecnologias digitais têm revelado, em âmbito nacional e internacional, o grande potencial do campo de saber da Informática na Educação Especial. Tem sido desencadeado um entrelaçamento das tecnologias digitais de informação e comunicação com um qualificado plano de atendimento especializado, um ajuste às especificidades e à variedade de histórias de vida de sujeitos em processo educativo, permitindo que a heterogeneidade e a diferença sejam lidas como vantagem e não como prejuízo. No entanto, recursos computacionais, por si só, não desempenham as funções esperadas se não forem mediados por professores formados sob os preceitos da Educação Inclusiva (SANTAROSA, 2006).

Para responder ao desafio de formação docente no âmbito das Tecnologias Digitais, e compondo a rede de formação continuada projetada pela SECADI/MEC, a Universidade Federal do Rio Grande do Sul (UFRGS), em especial o Núcleo de I nformática na Educação Especial ( NIEE) e o Centro Interdisciplinar de Novas Tecnologias na Educação (CINTED), vem desenvolvendo, há mais de dez anos, o curso Formação De Professores em Tecnolo- gias de Informação e Comunicação Acessíveis, com os objetivos de:

- Aperfeiçoar e formar em serviço, na modalidade a distância, via Internet, professores de escolas públicas inclusivas, com efetiva docência na Educação Básica, na apropriação e aplicação pedagógica das Tecnologias de Informação e de Comunicação com vistas à inclusão de alunos com necessidades especiais.

- Utilizar, no contexto educativo, Tecnologias de Informação, recursos computacionais de acessibilidade e objetos de aprendizagem, com criticidade e autonomia, para projetar a escola como tempo-espaço integrador de instrumentos de inserção sociodigital.

- Experienciar, projetar e desenvolver ações pedagógicas significativas mediadas pelas Tecnologias Digitais de Informação e de Comunicação e por recursos de acessibilidade alicerçados na premissa da inclusão sociodigital de sujeitos com necessidades educativas especiais no cenário sociocultural contemporâneo.

- Forjar uma ação integrada - docente e equipe de Atendimento Educacional Especializado (AEE) objetivando a construção de estratégias educativas para responder às diferentes demandas geradas pela inserção da diferença nas instituições educativas que compõem o Ensino Regular.

O curso Formação de Professores em Tecnologias de Informação e Comunicação Acessíveis, desenvolvido na modalidade a distância, utiliza as ferramentas de mediação e de comunicação disponibilizadas no ambiente 
virtual de aprendizagem, a plataforma Teleduc - metodologia de ensino ajustada à modalidade da Educação a Distância (EAD), que prevê o desenvolvimento de estratégias de aprendizagem e a publicação na plataforma do curso das atividades previstas para cada componente da base curricular, por meio de uma sequência de fases:

- Fase Sensibilização: apresentação e sensibilização às temáticas em foco por meio de conferências pela Internet e de ferramentas de comunicação síncrona (chat) e assíncrona (correio eletrônico, fóruns...).

- Fase I mersão: vinculação ao contexto da escola, diagnosticando a realidade escolar e trazendo casos existentes para a proposição das possíveis formas de intervenção.

- Fase Problematização: apropriação conceitual por meio de interações síncronas e assíncronas.

- Fase Consolidação: construção e reconstrução conceitual, apresentando os resultados edificados ao longo do processo de aprendizagem individual e coletiva.

A opção metodológica do curso centrase na interação de seus participantes - professores, formadores, tutores, coordenador - para edificar uma verdadeira comunidade virtual de aprendizagem. Esse curso tem a duração de 180 horas e apresenta a seguinte estrutura curricular (Figura 1):

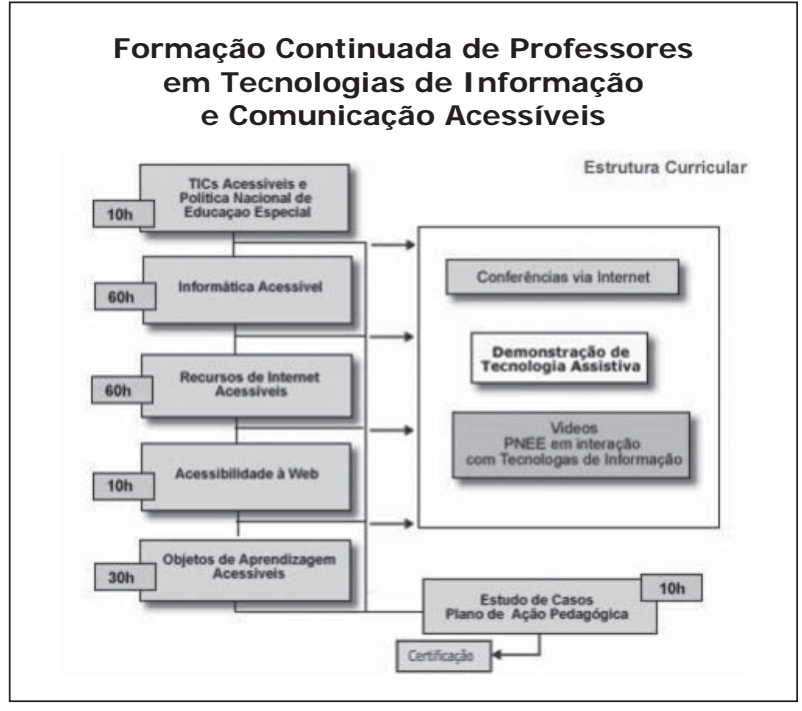

FIGURA 1 - Estrutura Curricular do Curso

FONTE: Elaborado pelas autoras.

Nessa perspectiva, dois níveis de uma formação docente em serviço são contemplados:

Nível 1 - Apropriação técnico-metodológica: O professor em formação articulará o domínio tecnológico com a prática pedagógica mediados por diferentes linguagens e ferramentas.

Nível 2 - Aplicabilidade na unidade educativa: O professor, em seu contexto educativo, deverá modelar estratégias de intervenção pela interface das tecnologias digitais e experienciálas com alunos com deficiência.

Ao longo da estrutura curricular são apresentados diferentes aspectos técnico-metodológicos relacionados às Tecnologias Digitais Inclusivas, tendo como fio condutor o campo de saber das Tecnologias Assistivas: 
Módulo I - Tecnologias de I nformação e de Comunicação Acessíveis e Política Nacional de Educação Especial - Contextualiza as Tecnologias de Informação e de Comunicação (TIC) na perspectiva da Educação Inclusiva. Impulsiona a apropriação de ferramentas de comunicação, interação e publicação individual e coletiva para mediar o processo de aprendizagem. Reflete sobre as políticas públicas, impulsionando a modelagem de planos de intervenção sociocognitiva, com vistas à inclusão escolar qualificada.

Módulo II - Introdução à Informática Acessível - Define e delimita Tecnologia Assistiva. Exploração, observação e manuseio de diferentes dispositivos e interfaces de hardware e software que possibilitam o acesso aos recursos de ambientes computacionais para a diversidade humana. Módulo de apropriação técnico-metodológica das Tecnologias Assistivas, aporte teórico para a utilização de alta tecnologia para a inclusão escolar.

Módulo III - Recursos de Internet Acessíveis - Estuda as possibilidades educativas da Internet acessível, consorciadas à Tecnologia Assistiva. Explora e reflete sobre os usos pedagógicos da Internet - navegação, comunicação e produção de conteúdo para Web - na perspectiva de uma Educação Inclusiva. Módulo IV - Acessibilidade à Web - Estuda critérios e requisitos para promover o acesso à Web para a diversidade humana. Observa e utiliza sistemas de avaliação e validação de conteúdo para a Web, consorciado à
Tecnologia Assistiva.

Módulo V - Objetos de Aprendizagem Acessíveis - Conceitua dimensões teóricas e metodológicas para a utilização de objetos de aprendizagem no contexto educacional. Realiza estudo ergonômico e cognitivo de objetos de aprendizagem na perspectiva da acessibilidade e da usabilidade. Analisa, avalia e explora objetos de aprendizagem, consorciados à Tecnologia Assistiva, que operem como instrumentos cognitivos para apoiar processos de inclusão escolar.

Nos Módulos II, III, IV e V, são estudados casos reais de inclusão escolar problematizados pelos conhecimentos e experiências vivenciados em cada um dos módulos, para assim elaborar estratégias técnico-metodológicas em apoio à diversidade humana, a partir da exploração das tecnologias que foram manuseadas ao longo do curso. As estratégias propostas são relatadas e discutidas entre os pares, construindo coletivamente alternativas de práticas inclusivas.

Módulo VI - Estudo de Caso e Plano de Ação Pedagógica - Explora a metodologia de projetos. Identifica, analisa e diagnostica Estudo de Casos de inclusão em instituições educativas regulares. Estruturar e aplicar plano de intervenção para a inserção qualificada de sujeitos com necessidades especiais no processo de escolarização.

Para os módulos descritos anteriormente, são oferecidos textos e matérias de apoio para a construção conceitual proposta em cada módulo. Além disso, várias conferências de renomados especialistas são apresentadas via Internet, com o objetivo de sensibilizar e 
promover a aproximação entre o professor e as temáticas que subsidiam e apoiam o processo de inclusão de alunos com deficiência na Educação Básica. Paralelamente, também são disponibilizados vídeos, inseridos nos conteúdos do curso, com demonstração de recursos de Tecnologias Assistivas, que possibilitam a efetiva participação de sujeitos com necessidades especiais, e com registros de experiências de uso das Tecnologias Digitais em contexto escolar, que ilustram a viabilidade de práticas de inclusão sociodigital.

A inserção de conferências e de vídeos que demonstram recursos tecnológicos e práticas de inclusão escolar, mediados por tecnologias digitais acessíveis, permite trazer e problematizar, para diferentes contextos, as áreas de conhecimento fundamentais para toda a dinâmica sociocultural brasileira. Para ampliar e qualificar a construção teórico-prática, projetada pelo curso, e forjar práticas de respeito e de valorização da diversidade humana, cada participante recebe atualmente o livro (Figura 2) Tecnologias Digitais Acessíveis (SANTAROSA, 2010) com todo material do curso, de autoria de pesquisadores do NIEE/ UFRGS, uma obra que propicia um aprofundamento da fundamentação teórica e a exploração de práticas significativas de inclusão sociodigital de pessoas com deficiência.

O governo brasileiro, por meio do Ministério de Educação (MEC), oferece gratuitamente a formação para docentes de países ibero-americanos, os quais recebem certificado pela Universidade Federal do Rio Grande do Sul (UFRGS). A plataforma EAD - TELEDUC é trabalhada na versão em espanhol, e as agendas, as atividades e o material de apoio que orientam a realização do curso são traduzidos para o espanhol. As interações são mediadas por formadores e tutores que dominam a língua espanhola. A partir de 2011, os professores-cursistas de língua espanhola terão acesso a essa publicação na versão em espanhol, Tecnologías Digitales Accesibles (Figura 2), beneficiando educadores de países ibero-americanos como Argentina, Uruguai, Chile, Colômbia, Panamá, Costa Rica, México, El Salvador e Espanha.
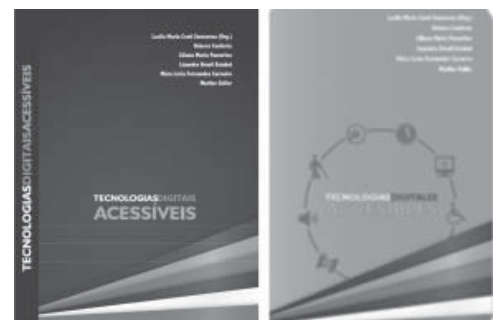

FIGURA 2 - Tecnologias Digitais Acessíveis e Tecnologías Digitales Accesibles, Material Didático Impresso do Curso.

FONTE: SANTAROSA (et al, 2010; 2011)

\section{Tecnologias Digitais Acessíveis: o foco na alta tecnologia}

O Curso de Formação Continuada de Professores em Tecnologias de Informação e de Comunicação Acessíveis coloca um especial destaque no campo de saber das Tecnologias Assistivas, sendo o módulo que verdadeiramente caracteriza o curso, momento em que o professor se apropria técnica e metodologicamente de recursos tecnológicos que de forma mais efetiva potencializam a inclusão sociodigital. As Tecnologias Assistivas são apresentadas aos educadores como interfaces de inclusão, os quais, ao mesmo tempo, são desafiados a experienciar esses recursos 
tecnológicos junto aos alunos em suas instituições educativas. No curso, os objetivos do módulo de Tecnologias Assistivas são:

- Desenvolver uma atitude positiva para a utilização das Tecnologias Assistivas como ferramentas de intervenção para Atendimento Educacional Especializado (AEE) e para potencializar a inclusão sociodigital.

- Conhecer o conceito de Tecnologia Assistiva, assim como a diversidade de tecnologias disponíveis, em especial, as que compõem as Salas de Recursos Multifuncionais dos Tipos 1 e 2 .

- Apropriar-se de conhecimentos técnico-pedagógicos de dispositivos e interfaces de hardware e software para favorecer o acesso a ambientes digitais para a diversidade humana.

- Explorar e manusear as Tecnologias Assistivas, objetivando sua aplicabilidade junto a alunos com necessidades especiais.

- Identificar e selecionar a Tecnologia Assistiva, a partir da observação e da sua adequação às especificidades sensoriais e cognitivas, para potencializar a inclusão sociodigital.

As atividades propostas no módulo de Tecnologias Assistivas são organizadas para aproximar os educadores desses recursos tecnológicos, objetivando a construção de interfaces de comunicação e de mediação pedagógica. A estrutura metodológica objetiva, de forma direta, a proficiência docente e, de forma indireta, e ainda mais importante, a educabilidade que projeta para a diversidade humana.

As atividades para o Módulo de Tecnologia Assistiva estão estruturadas ao longo de cinco semanas, propondo a mediação de tecnologias para diferentes especificidades humanas, sensoriais e motoras. A cada atividade proposta para o módulo de Tecnologia Assistiva, são associadas palestras com especialistas e vídeos com demonstrações de altas tecnologias, para subsidiar os professores em processo de formação e de discussão com seus pares.

Um movimento de apropriação técnicometodológico é projetado ao longo de todo o curso, com o objetivo de qualificar o olhar dos professores para os alunos com necessidades especiais em sua instituição educativa. Um ciclo de investigação é forjado por meio da observação de fragilidade e de potencialidades do público-alvo da Educação Especial, da análise da história de vida e da trajetória escolar de cada aluno em processo de inclusão escolar e do planejamento de estratégias de intervenção, para a aplicação de práticas de atendimento educacional especializado por meio da interface das Tecnologias Assistivas. Um processo de capacitação docente construído por meio da reflexão e do diálogo com seus pares, com formadores e tutores para a concretização do processo de inclusão escolar.

O módulo das Tecnologias Assistivas propõe, no espaço digital da plataforma do curso, a realização de cinco atividades, cada uma delas apresentando recursos tecnológicos relacionados às diferentes especificidades humanas. As atividades iniciais possibilitam conhecer e explorar Tecnologias Assistivas para apoiar o desenvolvimento e o processo de aprendizagem de alunos com diferentes necessidades especiais. Para cada Tecnologia Assistiva disponibilizada, uma atividade pedagógica é modelada para que o professor 
perceba a possibilidade de utilização desse recurso tecnológico no espaço da sala de aula, envolvendo todos os alunos. Essa estratégia permite que a Tecnologia Assistiva seja conhecida pelo aluno com necessidades especiais e seus pares, potencializando o uso da ajuda técnica junto aos demais professores.

$\mathrm{Na}$ atividade 1 , os professores-cursistas são apresentados e convidados à leitura de um conjunto de documentos, muitos deles disponíveis no Portal do MEC, para a apropriação conceitual da Tecnologia Assistiva (Figura 3). Essa atividade abre o módulo do curso com o objetivo de aproximação do professor-cursista com o campo de saber da Tecnologia Assistiva, para apropriação do conceito, da categoria e de sua aplicabilidade a fim de mediar interações da diversidade humana com o contexto sociocultural.

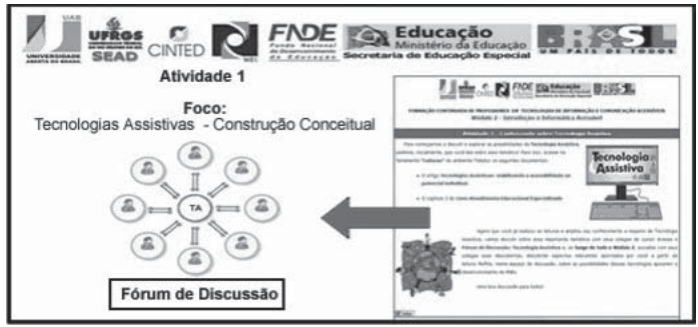

FIGURA 3 - Atividade 1: Tecnologias Assistivas, Construção Conceitual

FONTE: Elaborado pelas autoras.

Para aprofundar a discussão sobre a relevante temática da Tecnologia Assistiva, é indicada, ao professor-cursista, a leitura do Capítulo 7 do livro Tecnologias Digitais Acessíveis, em que o foco são as Tecnologias Assistivas. A construção conceitual é possibilitada pela abertura de um fórum de discussão, que se estende ao longo de todo o módulo.
Mensagens postadas no fórum, apresentadas a seguir, ilustram a descoberta, por parte dos educadores, desse importante campo de saber bem como a atuação da equipe de tutores e do formador na condução do processo de mediação do fórum:

Pra não ser repetitivo, quero dizer que estou aprendendo muito neste curso. Eu sou professor regular de uma sala de $4 \stackrel{0}{\circ}$ ano e tenho duas meninas com necessidades especiais. Antes de fazer este curso, eu não tinha consciência do arsenal que tinha na sala do AEE da minha escola. Já tenho um curso nesta área (Educação Especial), mas acho que a gente aprende mesmo quando se vê naquela situação prática e imediata. As TAs (termo novo mesmo!) se referem a qualquer instrumento utilizado que minimize as limitações técnicas, físicas e mentais dos estudantes com necessidades educativas especiais. Penso que não podemos considerar que estas tecnologias são avançadas, apesar dos estudos em EE serem novos, acredito que as famílias (de uma forma geral) já buscavam meios de possibilitar algumas aprendizagens. Penso também que é urgente a necessidade dos professores se apropriarem destas tecnologias para que nasçam realmente na escola.

Aluno - 2011/2

É importante lembrar que as tecnologias assistivas vão desde uma fita crepe que prende o papel à mesa, para que não solte com os gestos involuntários do aluno, a criação de um mapa com os contornos em barbante, até a utilização de equipamentos como mouse e ponteiros ou um software leitor de tela para acesso ao computador. Tudo que auxilie a aprendizagem, que proporcione a adaptação do aluno com necessidades especiais.

Aluna 2011/2 - Alfabetizadora

$\mathrm{Na}$ atividade 2, o professor-cursista em formação explorará Tecnologias Assistivas para apoiar usuários com limitações físicas e que, por algum motivo, não possam utilizar o teclado convencional como um dispositivo de entrada (Figura 4). Diferentes tipos de teclados são apresentados, todos livres, permitindo que sejam instalados no Laboratório de Informática, nas Salas de Recursos Multifuncionais ou no computador pessoal do 
professor, para que o mesmo possa continuar a explorar esses recursos, para garantir e qualificar o processo de mediação das estratégias de aprendizagem junto a alunos com necessidades especiais.

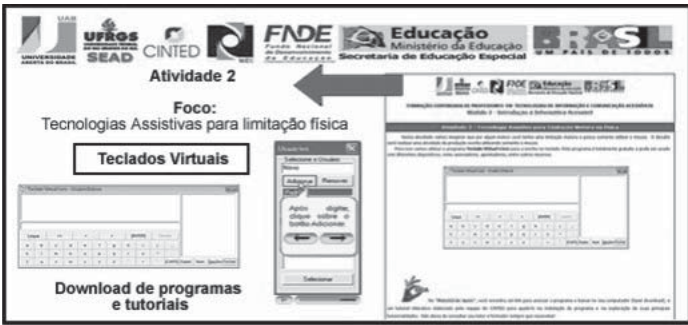

FIGURA 4 - Atividade 2: Tecnologias Assistivas Para Limitação Física.

FONTE: Elaborado pelas autoras.

A reflexão da professora-cursista sobre a exploração do Teclado Virtual Livre é apresentada para ilustrar o processo de apropriação tecnológica:

Digitar sem o uso do teclado foi um desafio, encarando uma situação totalmente nova e não habitual. Confesso que ainda não havia experimentado o teclado virtual. Como nova experiência, me deparei com algumas dificuldades e curiosidades. A primeira dificuldade foi achar o sinal de “ (aspas), espaçamento, como apagar a palavra, acentuação e precisei levar um pouco de tempo para me habituar com essa ferramenta. Mas após completar a frase já estava me sentindo bem à vontade com o teclado virtual. Sem dúvidas o simulador de teclado é uma ferramenta de extrema importância para a escrita de pessoas com deficiência física com os membros superiores comprometidos. Pois favorece a expressão da linguagem e do pensamento na forma escrita e é de fácil acesso pelo usuário. E em alguns casos, o uso de acionadores permite essa mobilidade para fazer um clique.

Aluno - 2011/1

$\mathrm{Na}$ atividade 3, o foco de investigação passa a ser o das Tecnologias Assistivas para sujeitos com limitações visuais (Figura 5). Os professores-cursistas exploram, entre outras tecnologias, leitores de tela, lupas eletrônicas e programas em Braile, seguindo a mesma metodologia exploratória proposta para as demais atividades: conhecer, manusear, planejar, aplicar, refletir.

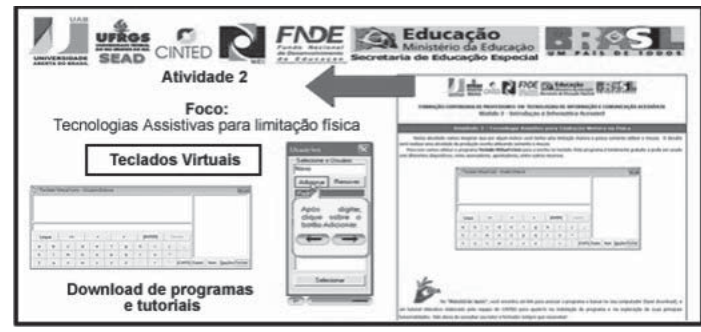

FIGURA 5 - Atividade 3: Tecnologias Assistivas Para Sujeitos Cegos

FONTE: Elaborado pelas autoras.

O professor-cursista é estimulado a manusear tecnologias disponibilizadas no cenário escolar na Sala de Recursos Multifuncionais, Tipo 2, uma significativa resposta ao desconhecimento dos educadores em relação à alta tecnologia para alunos com deficiência visual, como alerta o estudo realizado pela Comissão Temática da Educação do Ministério da Educação (2009). Recursos e equipamentos de alta tecnologia, como notebook ou computador com programas para alunos com deficiência visual, softwares e lupas eletrônicas, alcançaram o maior número de indicações sobre o desconhecimento da aplicação dessas tecnologias. Ao manusear o leitor de tela DOSVOX, a reflexão de uma aluna do curso aponta para a importância de capacitar educadores para o uso de recursos técnicos, principalmente, na possibilidade de constituir uma rede de multiplicadores das Tecnologias Assistivas para a inclusão sociodigital. 
[...] O programa DosVox é de extrema importância para o Deficiente Visual, pois permite o uso do computador e seu livre acesso à Internet. Sem questionamentos, é uma ferramenta brilhante em nossas mãos. É importante ressaltar a importância de um profissional especializado para orientar o seu uso a fim de explorar todos os importantes recursos que estão disponíveis. Desta forma, cursos desse tipo nos permitem, enquanto profissionais da Educação, sermos multiplicadores desses conhecimentos e aprendizagens levando acessibilidade aos nossos alunos com deficiências e favorecendo sua inclusão.

Aluna - 2011/1

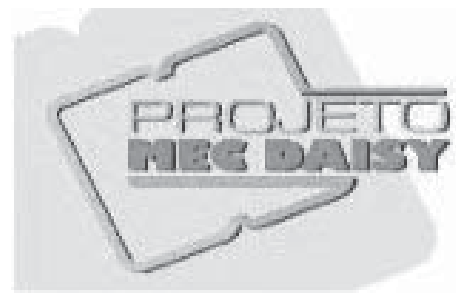

FIGURA 6 - Projeto MEC DAISY

FONTE: http://intervox.nce.ufrj.br/mecdaisy/

No curso de Tecnologias de Informação e de Comunicação Acessíveis, é dado um destaque ao aplicativo MEC DAISY (Figura 6), uma solução tecnológica que permitirá a produção de livros em formato digital acessível, no padrão Daisy, desenvolvido em NCE/UFRJ . O programa possibilita a geração de livros digitais falados e sua reprodução em áudio, gravado ou sintetizado. Com o programa MEC DAISY, sujeitos com limitação visual ou física podem ter acesso à leitura sob a forma de áudio e texto digital. O Ministério da Educação estabeleceu um acordo com as editoras responsáveis pela distribuição do livro didático às escolas públicas brasileiras, para a construção da versão digital desse material e para conversão em áudio de todo o livro, incluindo áudio da descrição das imagens, possibilitan- do acesso ao aluno cego. Foi realizada com todos os formadores do curso uma capacitação para o uso da tecnologia MEC DAISY.

A atividade 4 objetiva explorar recursos para apoiar o processo de comunicação (Figura 7). Nessa atividade, os professores-cursistas conhecem as possibilidades educativas dos sistemas de comunicação alternativa e aumentativa, entre eles os disponibilizados na escola nas Salas de Recursos Multifuncionias, como o software para a comunicação alternativa BoardMaker, por meio de vídeos de demonstrações. Para garantir que esse recurso seja ofertado à diversidade humana em diferentes cenários socioculturais de interação, o professorcursista tem acesso a programas não proprietários, o que permite a ampla utilização da Tecnologia Assistiva pelo aluno, não restringindo sua utilização somente à escola. A opção por tecnologias livres justifica-se por possibilitar a ampliação e a continuidade do processo de comunicação do aluno por meio de tecnologias no contexto familiar, permitindo que o processo de aprendizagem e de desenvolvimento seja significativamente potencializado. Links para download para obtenção dos sistemas de comunicação e tutorias para apoiar o processo de instalação e de utilização das tecnologias digitais são disponibilizados para os professores e para as instituições educativas.

Os professores-cursistas exploram técnicas de comunicação alternativas, recursos de alta e de baixa tecnologia, que objetivam ampliar as habilidades de expressão e de compreensão para sujeitos com limitações na fala. Conhecer, manusear e construir pranchas de comunicação permitem estabelecer e ampliar o repositório comunicativo de alunos 
com déficit na comunicação, uma intervenção que muitas vezes se faz necessária junto a alunos com paralisia cerebral.

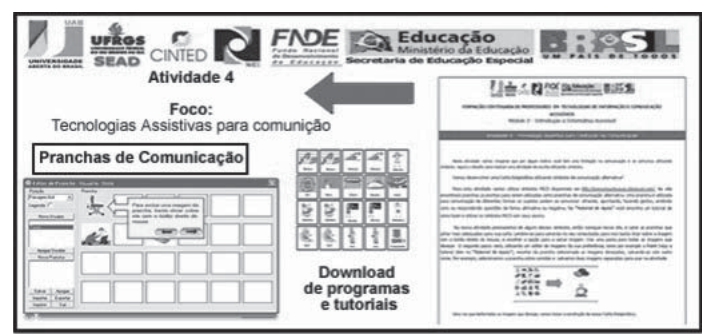

FIGURA 7 - Atividade 4: Tecnologias Assistivas Para Comunicação

FONTE: Elaborado pelas autoras.

Para afirmar o compromisso do curso em Tecnologias Digitais Acessíveis com uma proposta de formação na perspectiva técnica, mas também pedagógica, ao conhecer os sistemas computacionais para a edição de pranchas de comunicação e os símbolos gráficos, Picture Communication Symbols (PCS), os professores assumem o desafio de construir uma carta enigmática, que deverá ser decifrada por seus colegas de curso. Para realização dessa tarefa são utilizados diferentes recursos computacionais - editores de imagem, editores de texto e de apresentação além da pesquisa na Web dos símbolos PCS, desenvolvendo habilidades e formando competências que qualificam sua ação educativa no processo de atendimento especializado. A construção da carta enigmática (Figura 8) permite que o professor conheça os recursos gráficos de comunicação, uma importante estratégia para que o processo de comunicação seja efetivo na Sala de Recursos Multifuncionais, mas também nos diferentes tempos e espaços escolares. Um exemplo de carta enigmática e o comentário do formador são apresentados a seguir, exemplificando o compromisso com a formação técnica e pedagógica do curso.

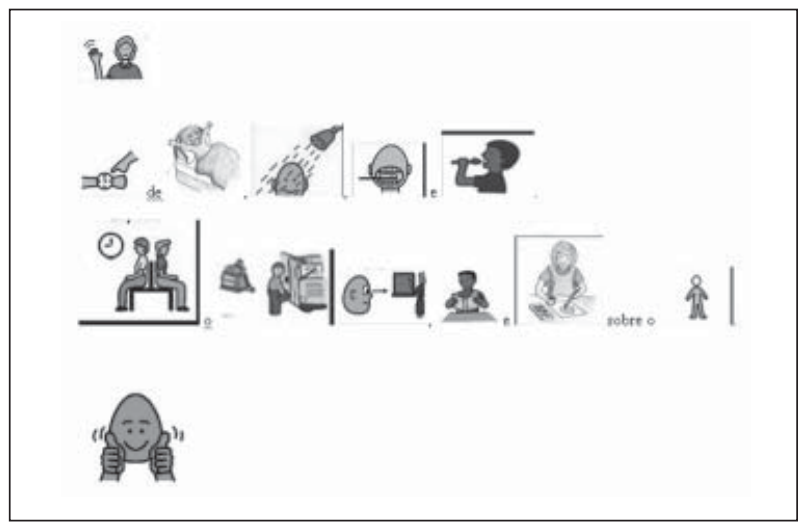

FIGURA 8 - Carta Enigmática com PCS Elaborada e Comentário da Formadora

FONTE: Elaborado pelas autoras.

[...] Como viste a CAA é um recurso que certamente pode proporcionar aos nossos alunos com déficit na fala, possibilidades de interação, aprendizagem e consequentemente de desenvolvimento. Ao se sentir incluído e participativo na rotina de classe e da escola, sua autoestima melhora gerando benefícios em todos os sentidos. Conseguiste passar na tua carta enigmática o que fazes no teu dia-a-dia, muito bem. Parabéns pela realização da atividade.

Formadora - 2011/1

A atividade 5 é a que faz o fechamento do módulo de Tecnologias Assistivas, momento em que o professor realiza análise de situações de inclusão escolar e, a partir dessa investigação diagnóstica, propõe estratégias de mediação por meio de Tecnologias Assistivas (Figura 9). É indiscutivelmente o momento mais significativo do módulo - estimular o professor-cursista a buscar, por meio das interfaces das Tecnologias Assistivas, a construção de estratégias educativas catalisadoras de práticas inclusivas. 


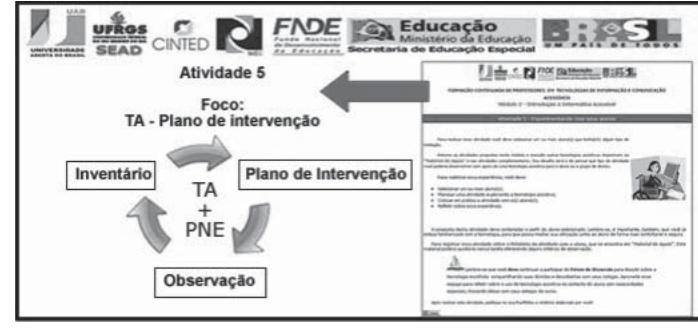

FIGURA 9 - Atividade 5: Estudo de Caso e Plano de Intervenção Pedagógica

FONTE: Elaborado pelas autoras.

Para apoiar todo esse processo de construção da intervenção, o professor-cursista é orientado a planificar sua estratégia. Para tal desafio, ele é convidado a observar alunos em situação de inclusão, em diferentes tempos e espaços escolares, mas principalmente na sala de aula, espaço em que por excelência a inclusão escolar deve ocorrer. $\mathrm{O}$ primeiro movimento é então desencadeado, a organização de um inventário, ou seja, um conjunto de perguntas que devem ser respondidas por todos que interagem com esse aluno, nos diferentes contextos em que o processo de aprendizagem e de desenvolvimento sociocognitivo ocorre.

Para planificar ações educativas que possam contribuir com o desenvolvimento de sujeitos com necessidades especiais, é importante observar esses sujeitos em interação com seus pares e em espaços sociais habituais, principalmente os de sala de aula. A partir desses dados é possível analisar o perfil sociomotor e cognitivo e, assim, identificar a tecnologia mais adequada e a metodologia necessária para suprir ou compensar déficits para que a autonomia de sujeitos com necessidades especiais seja possível. A elaboração do inventário para o aluno com necessidades especiais deve resgatar a trajetória escolar e analisar os registros das estratégias de apoio já implementadas e dos atendimentos a ele oferecidos. A visibilidade dessas informações subsidiará o professor-cursista na tomada de decisão de identificar a Tecnologia Assistiva mais adequada e de planejar sua estratégia pedagógica.

Analisadas as informações registradas no inventário, definida a Tecnologia Assistiva que de forma mais efetiva apoia o processo de comunicação e de interação entre o aluno com necessidades especiais e seus pares, colegas e professores, planificada a estratégia pedagógica, o professor aplica a atividade projetada, realizando um cuidadoso registro de todo o processo de interação do aluno com a tecnologia assistiva e com o desenvolvimento da atividade proposta. Os dados registrados ao longo do desenvolvimento da atividade, os pontos positivos e frágeis apontados no estudo de caso, serão colocados em discussão com os demais professores em processo de formação. Essa realimentação trazida pela equipe de formadores e demais colegas permitirá um replanejamento da ação proposta e a avaliação da Tecnologia Assistiva escolhida, ajustando-as ao perfil cognitivo do aluno com necessidade especial que participou como sujeito de pesquisa no estudo de caso.

\section{Resultados: a concretização de Políticas Públicas para a Educação Inclusiva}

O curso Formação de Professores em Tecnologias de Informação e Comunicação Acessíveis tem sua importância ratificada pela 
possibilidade de espraiar o saber e a materialidade da Informática na Educação Especial nos diferentes pontos de um país continental como o Brasil. Os dados quantitativos, com mais de cinco mil professores formados na perspectiva da Educação Inclusiva, já seriam suficientes para atestar a importância da formação continuada na modalidade a distância projetada pela SECADI/MEC, mas o que de forma significativa permite dar visibilidade à positividade dos cursos de formação são as palavras dos próprios professores que participaram do processo de formação continuada. A partir de instrumentos de avaliação do curso, professores afirmam o potencial das Tecnologias Digitais Acessíveis como pontes e rampas para a inclusão digital e social de pessoas com deficiência:

[...] na contribuição do curso no processo de inclusão e no avanço dos alunos no processo ensino e aprendizagem; na grande vantagem que o curso oferece para que os professores possam utilizar os recursos disponíveis com os seus alunos; no que um curso na modalidade a distância representa na possibilidade e no caminho para uma socialização sem fronteiras; na possibilidade de os professores terem condições de estar situados em seus locais de trabalho, aprendendo sobre as novidades do mundo tecnológico em uma sociedade tão excludente em que os alunos necessitam das tecnologias para estarem inseridos no contexto social. (SANTAROSA et al, 2008, p.8.)

Ao analisar e avaliar os impactos e movimentos desencadeados a partir desse curso, é possível dar visibilidade ao jogo experienciado pela formação a distância, em seus limites e possibilidades de intervenção para a superação de práticas educativas que colocaram a diversidade humana na exterioridade das atividades socioculturais. Muitos são os exemplos que podem demonstrar a concretização dessa importante meta de inclusão sociodigital.

Escolhemos um deles, por refletir a ação de dois atores na apropriação dos saberes e da materialidade da Informática na Educação Especial: o educador e o aluno. O recorte que apresentamos a seguir ilustra os saberes problematizados ao longo de cada módulo do curso, cristalizados na conquista de uma menina que, por problemas físicos, ficou à margem de muitas experiências educativas em sua trajetória escolar. Um novo olhar para a diversidade humana aconteceu em um município do interior brasileiro - uma ação ética e estética de respeito e valorização da diversidade humana, apontada nas palavras da professora:

Não tenho palavras para expressar o quanto o curso em tecnologias digitais acessíveis está sendo gratificante para mim. D. é uma linda menina, teve parte dos membros superiores e inferiores amputados aos 3 anos; hoje, aos 10 anos de idade, nos surpreendeu com sua alegria e vontade de vencer tudo que Ihe é proposto a fazer. No computador, mesmo sem ter contato antes, parece que já é íntima dessa máquina, dominou o mouse como qualquer outra criança, ou até melhor. Como ainda não temos acessórios corretos, ela utilizou, para digitar, um lápis com uma borracha na ponta para não escorregar nas teclas, mas em breve vou providenciar um adaptador para que ela possa utilizar os dois braços. Fiquei admirada com o teclado de conceitos, o ponteiro de cabeça que pode ser afixado diversos tipos de acessórios, possibilitando teclar, pintar, pegar objetos, a tela sensível ao toque, o reconhecimento de voz. Foi fundamental para que eu tivesse uma visão mais ampla do funcionamento das tecnologias acessíveis e de suas possibilidades educativas. Eu não imaginava que isso era possível.

Aluna - 2008/2009

A partir dos resultados apresentados, percebe-se a importância e a eficácia da formação de professores para o uso das Tecnologias Digitais, permitindo que o aluno com 
necessidades educativas especiais conquiste o direito à comunicação, à pesquisa e à autoria, para, assim, modelar a interface de uma Escola Inclusiva. Nesse sentido, é essencial ao professor em formação que se efetive o entrelaçamento da teoria com a prática, a fim de impulsionar a construção de um olhar mais positivo para a diferença e de experienciar os saberes e a materialidade dos recursos disponibilizados pelo curso em atividades in loco, assumindo, então, o papel do educador-pesquisador. O jogo que se estabelece entre teoria e prática é de grande valia para o levantamento do potencial do aluno, para explorar, vivenciar e problematizar práticas de respeito à diversidade humana por meio de recursos tecnológicos acessíveis:

Ao iniciar este curso minha ansiedade pelo novo era muito grande. Grande por ter dificuldades em operar com a tecnologia. Hoje, me encontro mais confortável em relação ao ambiente virtual. [...] $\mathrm{O}$ importante deste curso, além do conhecimento teórico, é a prática que valida toda a aprendizagem. Os recursos apresentados são de certa forma, seguindo o passo-a-passo, simples. A cada atividade que consigo realizar, com mais segurança e tranquilidade, me sinto recompensada. A recompensa está em ver e sentir que as tecnologias assistivas são, no primeiro momento COMPLICADAS, mas ao conhecê-las, experimentá-las, passam a ser GRANDES aliadas no nosso trabalho. O repasse das tecnologias assistivas para o nosso público é a confirmação de que vale a pena fazer este curso, vale a pena estar mais preparada, vale a pena saber utilizar as tecnologias. É muito bom estar nesta turma e melhor ainda estar conhecendo tecnologia assistiva através desta equipe gabaritada, formador e tutor.

Aluna - 2011

Acreditamos que precisamos olhar para o futuro, pensar e repensar o tempo e o espaço de aprendizagem para a diversidade humana, superar o todo normal e homogêneo que persiste em muitas práticas escolares, para que se possa vivenciar o inédito-viável, sempre tão sonhado pelo educador Paulo Freire
(1992), ao compreender a história de vida de cada sujeito com deficiência na visão utópica da possibilidade e na superação da visão fatalista do determinismo genético. A situação limite que se institui pelo isolamento e distanciamento do padrão estabelecido de normalidade tem, na mediação tecnológica, a possibilidade de incluir a diferença para instigar o fazer coletivo como forma de compartilhar e modelar projetos de vida.

A importância de propostas de formação como as vivenciadas nesses mais de dez anos de sintonia e parceria entre UFRGS (NIEE/CINTED) e MEC ilustra a positividade do estreitamento de laços entre a universidade pública e a escola de Educação Básica, numa parceria de via de mão-dupla, sem hierarquização de saberes, mas com transversalidade do trabalho colaborativo, que assumiu, como escopo, a configuração de uma educação pública de qualidade para todos. Os espaços que se forjam para as trocas de experiências entre diferentes países ibero-americanos também representam a construção de interfaces acessíveis que, ultrapassando os limites geográficos de países e ampliando dimensões de territórios culturais locais, os quais, embora com idiomas diferenciados, possuem contextos e histórias similares, passam a traçar novos rumos em direção à construção conjunta de uma sociedade global mais igualitária.

Vivenciando um exercício de autonomia e de concretização de políticas públicas para a inclusão escolar, a rede de formação continuada projetada pelo MEC vem possibilitando que professores conquistem o poder da palavra, tornando visível a riqueza de atuações de educadores. Professores, em sua maioria isolados no cenário multicultural, 
vivendo a carência de recursos materiais e humanos, são estimulados e desafiados pelos saberes técnicos e metodológicos de Tecnologias Digitais Acessíveis para a cons- trução e vivência de um espaço digital educativo, para o convite a um fazer pedagógico alicerçado no real exercício da lógica da inclusão.

\section{Referências}

BRASIL. Decreto n. 6.571, de 17 de setembro de 2008. Dispõe sobre o Atendimento Educacional Especializado, regulamenta o parágrafo único do art. 60 da Lei no 9.394, de 20 de dezembro de 1996, e acrescenta dispositivo ao Decreto no 6.253, de 13 de novembro de 2007. Brasília, 2008. Disponível em: <http: //www. planalto.gov.br/ccivil_03/_ato2007-2010/2008/Decreto/D6571.htm> Acesso em: dia mês abrev. ano.

BRASIL. Subsecretaria Nacional de Promoção dos Direitos da Pessoa com Deficiência. Comitê de Ajudas Técnicas. Tecnologias Assistivas. Brasília: CORDE, 2009.

EMER, S. Tecnologia Assistiva Como Instrumento de Inclusão Escolar: sala de recurso multifuncional e sala de aula. 2011. Dissertação (Mestrado em Educação) - Programa de Pós-Graduação em Educação, Faculdade de Educação, Universidade Federal do Rio Grande do Sul, 2011, Porto Alegre, BR-RS.

FREIRE, P. A Pedagogia da Esperança: um encontro com a pedagogia do oprimido. Rio de Janeiro: Paz e Terra, 1992.

FREIRE, P. Pedagogia da Autonomia: saberes necessários à prática educativa. São Paulo: Paz e Terra, 1996.

RODRIGUES, G. E se os Outros Puderem me Entender?: os sentidos da comunicação alternativa e suplementar atribuídos por educadores especiais. 2011. Dissertação (Mestrado em Educação) - Programa de Pós-Graduação em Educação, Faculdade de Educação, Universidade Federal do Rio Grande do Sul, 2011, Porto Alegre, BR-RS.

SANTAROSA, L. M. C. ; PASSERINO, Liliana ; CARNEIRO, M. L. ; GELLER, Marlise; CONFORTO, D. Ambientes Virtuais para Formação de Professores em Informatica na Educação Especial: construindo acessibilidade. In: IX Congresso Iberoamericano De Informatica Educativa, 2008, Caracas. Memorias do Congresso I beroamericano de Informatica Educativa, 2008. v. 1. p. 1-8.

SANTAROSA, L.M.C. Paradigmas Educacionais Para a Construção de Ambientes Digitais/Virtuais, Visando Pessoas com Necessidades Especiais - PNEEs. In: CONGRESO TECNONEET - CIIEE 2006, 2006, Murcia. As Tecnologias na Escola Inclusiva: novos cenários, novas oportunidades. Murcia: FG Graf., 2006. V. 1, p. 
35-42. Palestra proferida na sessão de encerramento do evento.

SANTAROSA, L.M.C. (Org. ). Tecnologias Digitais Acessíveis. Porto Alegre: JSM Comunicações, 2010.

SANTAROSA, L.M.C. (Org. ). Tecnologías digitales accesibles. Porto Alegre: JSM Comunicações, 2011.

\section{Lucila Maria Costi Santarosa}

Núcleo de Informática na Educação Especial (NIEE), Universidade Federal do Rio Grande do Sul (UFRGS). Porto Alegre RS - Brasil. E-mail: lucila.santarosa@ufrgs.br.

\section{Débora Conforto}

Núcleo de Informática na Educação Especial (NIEE), Universidade Federal do Rio Grande do Sul (UFRGS). Porto Alegre RS - Brasil. E-mail: deboraconforto@gmail.br. 